\title{
The value of heritage in sustainable development and spatial planning
}

\author{
Koenraad Van Balen and Aziliz Vandesande
}

\section{Cultural heritage and sustainable development}

UNESCO's Hangzhou Declaration (2013) attempted to rectify the omission of culture in the millennium goals. Anticipating the revision of the millennium goals in 2015, the conference and document presented culture as the fourth pillar of sustainable development, in addition to the three recognized 'pillars' of society, environment and economy. However, the Sustainable Development Goals (SDGs) (2015) that resulted from the revision did not sufficiently reflect the valuable contributions of the Hangzhou conference, in particular, the potential contribution of cultural and cultural heritage to sustainable development. The concept of culture as the fourth pillar was introduced in Hawkes's work Fourth Pillar of Sustainability: Culture's Essential Role in Public Planning (2001). Recognition of this was made explicit through his contribution to the UNESCO conference, more than ten years after his publication. Although the concept of the fourth pillar helps make the role of culture in sustainable development explicit and visible, today we may wonder, without entering too much into a conceptual debate, whether the lack of integration of culture into the sustainable development concept (as in the SDGs) is due to not explicating how the 'environment', 'society' and 'economy' each have a cultural dimension. But, as is often the case in the cultural heritage sector also, the obvious is overlooked and overruled by manifestations of the powerful. The integral nature of cultural heritage then hampers its visibility and position.

The consortium led by Europa Nostra that published the influential report Cultural Heritage Counts for Europe (CHCfE Consortium 2015) was asked to develop a method to measure and define the impact of cultural heritage in 
Europe. We proposed using the four-pillar concept to analyse the impact of cultural heritage for Europe, identifying its contribution to sustainable development. The collected evidence allowed the research team to systematically identify the contribution of cultural heritage to the sustainability of different types of efforts (e.g. education) and resource streams (e.g. resources earmarked for transnational collaboration, as in the Interreg programmes). This can be considered a major contribution to a change in perspective on the impact of cultural heritage, which has been summarized as the 'upstream approach'. In this chapter we will highlight some of the findings and policy recommendations from the work. In the second part, based on the developed four-pillar concept, we propose a sustainable management and development framework that can help translate these Europe-wide findings into local contexts, and thus integrate cultural heritage into local development strategies.

\section{Collecting evidence in four dimensions}

Based on a literature review, we developed an understanding of the wider context and trends and revealed existing qualitative and quantitative indicators to measure the contributions of cultural heritage to the four pillars. Next, we collected the main body of data through an online survey (December 2013-September 2014) of representatives of institutions working in the fields of culture and heritage, academics and organizational employees in European Union (EU) member states. We complemented this data with expert collaboration and desk research. Expert collaboration was especially important in the context of Central Europe, a region of great linguistic diversity and a lack of formal data and accessible impact studies. 'National' experts, all scholars specializing in various aspects of cultural heritage management, were asked to search for relevant data and text in their native language to insert in an English-language survey. Moreover, in a 'Central European Round Table on Cultural Heritage' held in Krakow (October 2014), experts from the region, joined by colleagues from Western Europe, discussed, analysed, compared, contrasted and verified the findings.

In total, 221 entries to the online questionnaire were generated by external input and the research partners. In the analysis of the data, we identified subdomains of cultural heritage impact within the four pillars. The analysis of the data also allowed us to identify trends (in time and space) regarding the understanding of the dimensions that express the impact of cultural heritage. 
For more detail, we then looked at a selection of case studies to illustrate possible approaches to assessing the impact of cultural heritage in a local context. We studied in more detail such generally considered 'good practice' case studies as Mechelen (Belgium) - a historic city in Flanders characterized by its outstanding cultural heritage - and Łódź (Poland) - the renovation and modernization of the Gallery of Polish nineteenth-century Art and the conversion of a nineteenth-century factory building into the Muzeum Sztuki. For each of the case studies, collecting local data allowed us to identify the impact on the four domains of sustainability. The micro-level research was complemented by an analysis of 40 valid responses to a specific questionnaire, received from winners of the EU Prize for Cultural Heritage/Europa Nostra Awards between 2002 and 2014, using Europa Nostra's approach for assessing the impact of the winning projects.

\section{Presenting findings in four dimensions}

The findings and the policy advice distilled from the Cultural Heritage Counts for Europe report are available online (CHCfE Consortium 2015). In this chapter we highlight those findings that refer to the contribution of cultural heritage to wellbeing and practices of good planning. Based on the four pillars of sustainability, the project defined the 'holistic four domain approach to the impact of cultural heritage'. This is illustrated in the central figure (p. 60) of the report (Figure 3.1).

The scheme allowed us to fine-tune the identification of the possible impact of cultural heritage, and the contributions of the overlaps of different fields (or pillars) to sustainable development. It is obvious that the planning aspects or aspects of wellbeing require a multidimensional approach to benefit especially from the overlaps of the four dimensions. The study's hypothesis, therefore, was that the more overlaps exist, the more sustainable the development is.

While 'sustainable development' was initially defined as 'development that meets the needs of the present without compromising the ability of future generations to meet their own needs' (WCED 1987: 43), since then the concept has mainly focused on ecological, economic and human or social dimensions. Throsby's argument for liberating the word 'sustainable' from its environmental connotation - he proposed to use it in 'its substantive intrinsic sense connoting long-term self-supporting viability of any type of system' - has led to the understanding that culture itself can be seen as sustainable (Throsby 1997: 10-11). 


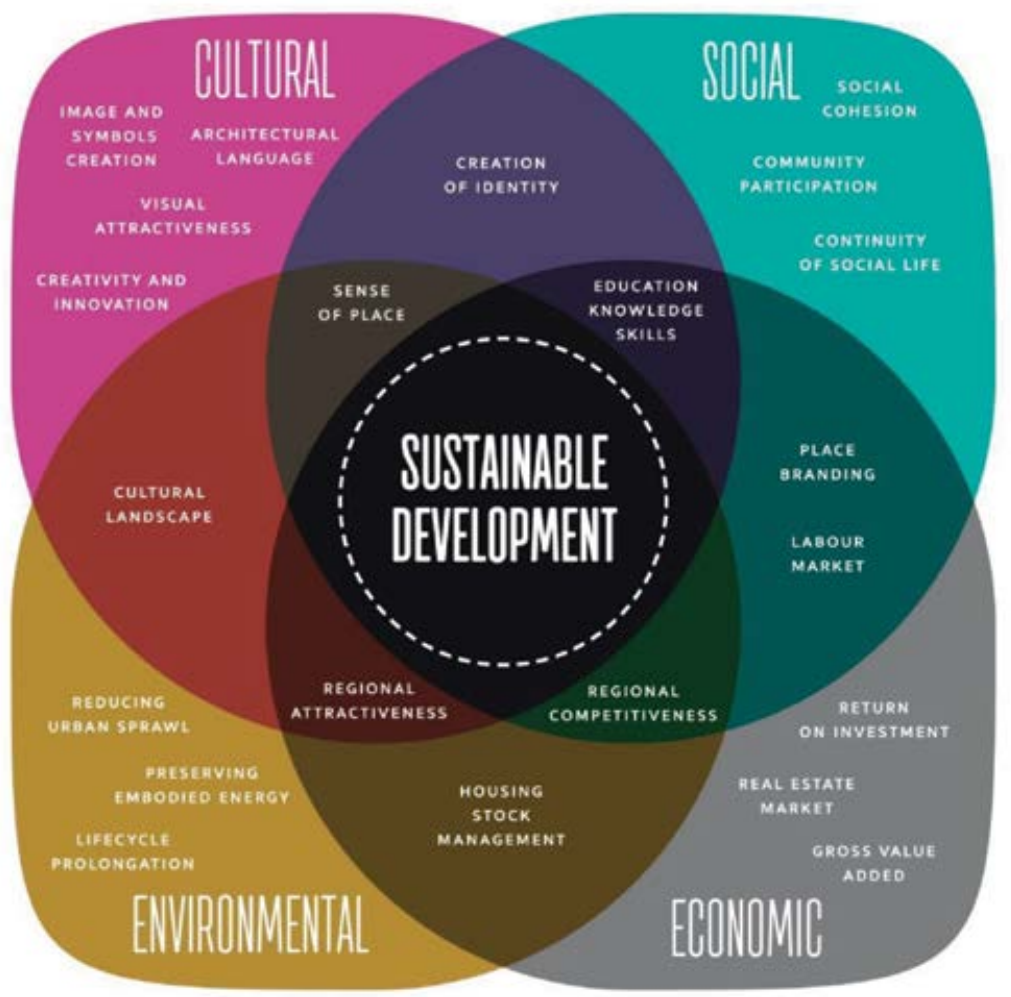

Note: (c) CHCfE Consortium.

Figure 3.1 Sustainable development and the four pillars

Various publications and practices collected during the project demonstrated that efforts or investments earmarked for economic, social, environmental or cultural purposes, when invested in the safeguarding of cultural heritage, resulted in an impact in one or more of the four domains. Cases of 'pure' economic investment to safeguard cultural heritage (e.g. certain types of investment in tourism) resulted in positive impacts beyond that. For example, such investments were found to positively affect the social domain (e.g. better mutual understanding among people from different backgrounds), the environmental domain (e.g. reuse of existing buildings) and the cultural domain (e.g. boosting of cultural practices). Similarly, sociocultural projects such as the reconciliation programmes in the Balkans, which invested in safeguarding 
of cultural heritage for peacebuilding, also resulted in positive impacts on the economic and environmental domains.

The study demonstrated that safeguarding cultural heritage acts as a 'diffuser' or 'multiplier' through which investments or efforts have impacts on multiple domains beyond the domain they are earmarked for. This increased the effect as well as the level of sustainability of the outcome. We showed, then, that resources that are not necessarily or directly earmarked for cultural heritage can still be aligned with heritage activities, and have the potential to improve their sustainability. This confirms the 'upstream' perspective (see 'Figure 4.3 "Upstream" perspective on cultural heritage impact' in CHCfE Consortium (2015)) on built heritage impact, whereby traditional investment schemes are linked with resources from other sectors. This implies that introducing non-heritage funding into the context of built heritage, to achieve non-heritage goals such as social cohesion or reducing unemployment, can improve heritage while also improving the sustainability of the outcome of the funding. For example, the cultural integration of such interventions can generate more acceptance and increase the carrying capacity of the community, resulting in more lasting outcomes.

In that sense, sustainable planning should acknowledge the contribution of cultural heritage in domains which at first sight do not seem related to culture. Connecting cultural heritage to those other drivers is the essence of the upstream approach. This is based on the 'trading zone' approach, used in anthropological sciences to define specific interdisciplinary collaborations. Although sectors have different objectives and viewpoints, they use forms of exchange by building an intermediate language, which allows them to communicate and create new cooperation (Galison 1997). The work of Gustafsson (2009) introduced the 'trading zone' concept to the built heritage field through the 'Halland Model' experience in Sweden, whereby traditional financial investment schemes allocated with built heritage conservation were augmented with resources from other sectors; that is, employment and the labour market (Vandesande 2017).

The upstream model starts by inducing impact with resources from a single sector on a multitude of sectors through the successful introduction of new or altered processes and organizational structures. This process generates a growth in output that exceeds the growth in inputs; that is, productivity growth (Fox and Van Rooyen 2004). Thereby, the innovative economic process aims at cross-sectoral collaboration to ensure sustainable built heritage management, while inducing local productivity growth, innovation and development. 
Figure 3.1 shows how such sub-domains as 'sense of place'; 'regional attractiveness', 'regional competitiveness' and 'knowledge creation and skill building', which are embedded in non-cultural domains, can benefit from a cultural component to enhance their sustainability. The study has identified many such examples in which cultural heritage contributed by providing a cultural component. We illustrate a few of them below.

\section{Cultural heritage versus the environment}

As identified in Figure 3.1, cultural heritage can contribute to increasing the sustainability of the environmental pillar by adding (at least) a cultural dimension to it. There are various ways this contribution could be made explicit. The first is quite straightforward, through the reuse of existing (heritage) buildings. The (often economic) driver to replace them with new constructions is reduced. From a material sustainability evaluation point of view, the most sustainable construction is indeed the one that has already been built. The deposit (and thus waste) of existing embodied energy through demolition of existing buildings, and the need to create additional embodied energy (including labour, transport and raw material) in new construction, signifies a double environmental loss. New constructions can have higher energy performance, but often the embodied energy is overlooked in calculations of overall energy use (Lidelow et al. 2019).

Another way to make more explicit the contribution of cultural heritage to sustainability is to understand cultural heritage as a knowledge depository; an accumulation of different forms of knowledge and experience. To illustrate this, take the above-mentioned aspect of energy savings in buildings (to reduce carbon dioxide emissions and the use of non-renewable resources). Considering traditional construction technologies, it should be understood that traditional societies had difficulties in gaining access to energy and materials and were - as we are today - driven towards energy- and material-saving (local) solutions. These solutions were, of course, defined in their respective sociotechnical ecosystems, jointly considering social, economic and technical boundaries, and were adapted to their respective local environmental conditions. Thanks to slow but not less effective empiric evaluation systems, these solutions have evolved and become most effective; an effectiveness it is challenging to understand in today's global world, based on universal models. Recognizing the power of example and respectfully identifying solutions developed in the past - which can be found in cultural heritage, whether archives, practices or material examples - are valuable resources to preserve, 
and also valuable sources of information to identify local sustainable solutions. An obvious example is the recognition of the durability and sustainability of earthen constructions in many parts of the world. These can deliver appropriate hygro-thermic living conditions, often provide good resistance to earthquakes and can easily be maintained by local craftsmen using local materials. Adding to this rather technical consideration, adapted local behaviour such as seasonal dressing and practices of how buildings were used were also ways to deal with the same socioeconomic technical ecosystem. Some of these practices are considered (intangible) heritage. The diversity of possible and comfortable personal responses to different boundary conditions, even today, is something models do not take into account. There are thus good arguments for considering cultural heritage in support of environmentally driven sustainable efforts of society today, for example, the adapted reuse of existing and historic constructions.

\section{Integrating cultural heritage into local sustainable development through a systemic approach}

In this section, the social, economic and cultural pillars are addressed through the Sustainable Management and Development (SMD) framework (Vandesande 2017), developed within the UNESCO Chair on Preventive Conservation of Monuments and Sites at KU Leuven. This identified that a preventive approach requires an integrated and systemic approach (Van Balen 2015). Here we aim to connect this systemic approach, based on preventive conservation, to local sustainable development; analysing built heritage, which is by definition bound to locations. Based on the previously described upstream approach, this implies that cultural heritage is not positioned in the core of the model, but local sustainable development is. This allows us to identify the contribution of cultural heritage to the overall process, and to identify the complementary needs and resources.

Many built-heritage-preservation-centred projects have aimed to centralize efforts and resources on the preservation of the fabric, often overlooking the cultural, social and intellectual rationale for sustainable management (Vandesande 2017). The disproportionate investment of financial and societal resources in large, often prestigious heritage interventions, without considering sustainable heritage quality protection, has often proven to be inefficient. One example would be large investments in heritage preservation which eventually result in restored buildings without proper management capacity. 
Preservation of heritage values relates to the protection of the intrinsic quality of the built heritage. It therefore requires the specialized knowledge and skills of individuals involved in the management and intervention process; but how can this be connected to local sustainable development? Communities in historic urban and rural environments with their own local specificities also influence built heritage management, and their active participation can increase social capital and strengthen local networks. The SMD framework shows how interrelating all these thematic patterns, combined with a closer integration of built heritage into other sectors, entails that sustainable built heritage management can become a source for local development (Figure 3.2).

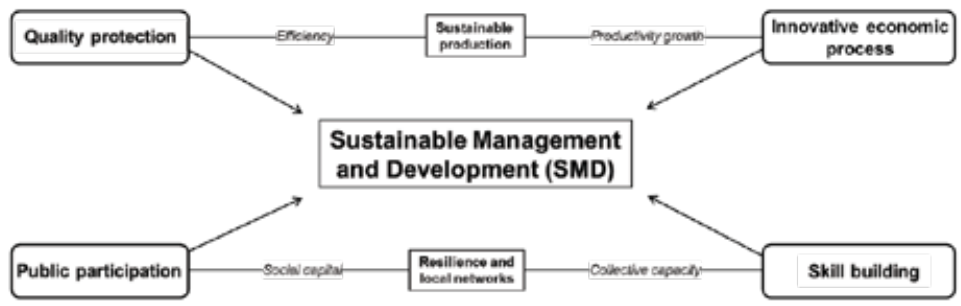

Source: Vandesande (2017).

Figure 3.2 The SMD framework

Within this framework, heritage-quality protection is the starting point of (ideal-typical) sustainable built heritage management as, at the end, 'quality' refers to the protection of heritage values. Managing built heritage through the framework, thereby placing local development at the core, combined with productivity growth based on new or altered processes following the upstream model, entails sustainable 'production' for built heritage. Here, 'production' refers to the process of managing built heritage, which is sustainable due to the efficient use of resources and the long-term capacity to sustain this production through operationalizing an innovative economic process that fosters productivity growth.

The four components of the SMD framework represent components of a system contributing to preventive conservation; they also refer to the interrelationships between dimensions that help to enhance sustainability in line with the upstream approach. 


\section{Quality protection}

The first SMD framework component is quality protection; a loaded term with multiple relations to built heritage. The most direct relation concerns the physical fabric, including both building condition and performance and the authenticity and integrity of the heritage asset. Considering that built heritage structures themselves are the most important repository of heritage values, historic materials and construction techniques, their long-term value-based sustainable management depends on the quality of interventions, considering the complexity of existing historic structures, the specificity of historic building materials and techniques, workmanship, workability and the stakeholders who influence the intervention. These variables determine the durability and performance of interventions and the avoidance of waste of materials, energy, efforts, money and time. The quality of interventions therefore depends on balancing these variables during the built heritage management process. The quality protection of intervention results in efficiency, or the optimal use of resources in realizing the objective (Fox and Van Rooyen 2004); that is, sustainable management of built heritage.

In understanding built heritage as 'ingrained' in the urban environment, the quality of the historic urban environment should also be considered. Research from the building information field endorses this long-term perspective, stating that 'sustainable management of the built environment requires the preservation of both natural capital and man-made resources, which means using artefacts for as long as possible' (Kohler et al. 2009: 451). The physical quality protection of historic cities and public spaces can foster social inclusion, citizenship and place prosperity for local residents (Gallacher 2005). Moreover, the quality of the historic built environment can also induce 'multiplier' and 'derived' effects (Bowitz and Ibenholt 2009); the presence and 'attractiveness' of built heritage in an urban environment also holds a large potential for local development (CHCfE Consortium 2015). Risks of inequality via gentrification should also be considered. All these factors demonstrate relationships with the different pillars mentioned earlier.

\section{Innovative economic processes}

The need for public sector policies and support measures to conserve built heritage has long been advocated at a European level, specifically through the Council of Europe (CoE). Resolutions of the Committee of Ministers first brought attention to funding issues in the 1960s and 1970s, including administrative, financial and intervention measures (Pickard 2011). Since the 2000s, a considerable amount of research has been conducted on alternatives 
to increase private investment, including limited liability companies, revolving funds, concession agreements, transfer of development rights, grant-aided subsidies, loan and credit facilities and fiscal measures (Pickard 2009). These alternatives mostly focus on short-sighted instrumentalization of built heritage and are often not linked to a sustainable management process, failing to take into account the ever-increasing demand for funding and the costs of long-term property management (for maintenance and so on) (Della Torre 2010). The CHCfE research identified how economics was, for a long time, the principal pillar addressed in publications on cultural heritage, whereas most recent publications on more sustainable examples combine the economic pillar with others. The upstream approach concept therefore explains how traditional investment schemes, when linked to resources from other sectors, make outputs more sustainable.

\section{Skill building}

The third SMD framework pillar, 'skill building', is most directly related to concerns from stakeholders involved in built heritage interventions, for whom skill building can ensure an ongoing dedication to quality protection and high standards in service delivery. While skills can be seen as practices related to intangible heritage, they are simultaneously instrumental to the preservation of the quality of built heritage. Also, contractors and conservators who implement manual labour require adequate skills to do so. Unfortunately, in Western Europe, a steepening decline is observed in the availability of experienced (heritage-specialized) contractors, trades- and craftspeople who have adequate knowledge, skills and competence (Hutchings and Corr 2012). Skill shortage and tacit knowledge transfer (due to a 'greying' labour force) is still today perceived as a growing problem which is commonly attributed to a lack of training for contractors or inadequacies in professional training for specialized built heritage activities (Swallow 1997; Wood 2005). The lack of awareness among youngsters (and their parents) when choosing their professional career, and of the benefits of heritage professions, also seems to play a crucial role.

In addition to skill building on an individual level, local capacity building (i.e. self-organization) and the capacity for adaptation to strengthen resilience and sustainable management (Tidball and Krasny 2007), is becoming more important in international and European policy (Smedby and Neij 2013). In the specific context of historical urban and rural environments, multilevel governance - the entanglement between various levels of authority - is defined as a prerequisite for resilience and sustainability (Dieleman 2013), necessitating capacity building between different levels and actors (Folke 2006). In practice, several analytical frameworks on multilevel governance and capacity building 
have been developed and tested through empirical work, demonstrating effects on local sustainability (Holden 2010) and social learning processes (Loorbach 2007). Sustainable management of historical urban and rural environments implies strengthening the capacities of local stakeholders to take into account social, economic and organizational conditions and understand what change is required in response to external influence. In this way, specifically strengthening local urban governance capacities helps sustain the quality of cities (Magalhães et al. 2002).

\section{Public participation}

The origins of the discourse on public participation trace back to the 1970s (Council of Europe 1975 European Charter of the Architectural Heritage, art. 9 and UNESCO 1976, art. 21). This issue gained increasing focus during the 1990s (Smith et al. 2003), when the responsibility for built heritage conservation was shifting from expert- and government-oriented practice to more participatory management approaches involving local stakeholders (Vandesande et al. 2012). Today, public participation, community involvement and engagement of civil society are increasingly activated within built heritage interventions to ensure long-term sustainability of the management process. This approach is reflected in the concept of the 'heritage community', as articulated in the 2005 Faro Convention, and in different actions by the EU to involve civil society in its activities in the field of culture since the adoption of the European Agenda for Culture in a Globalizing World (2007). There have been several successful case studies relating to built heritage management and community involvement (Van Balen and Vandesande 2015).

Next to ensuring long-term sustainability of the management process, public and civil society participation in built heritage has also gained recognition as an important factor in development (World Bank 2002). More specifically, participation processes create local networks which are based on continuous interaction and mutual trust (Magalhães et al. 2002). Within these networks, social capital is generated through 'social processes which turn information into meaningful knowledge and knowledge into action' (Innes 1995: 185). That is, networking through the engagement of the local community (Lampis 2009; Canziani and Moioli 2010) and personal mastery through skills such as self-awareness, communication, collaboration and participative actions (Dieleman 2013). Research on social capital demonstrates that this process improves living conditions in the whole community (Isserman et al. 2009), facilitates cooperation for mutual benefit and, in turn, enhances the benefits of investment in physical and human capital (Putnam 1993). Moreover, participation processes in built heritage can foster a local identity in times of 
economic and cultural globalization (Swensen et al. 2012) or create a larger community identity of which non-inhabitants are also proud (Hewison and Holden 2006).

\section{Conclusion}

In this chapter we explored the concept of the upstream model, which illustrates how cultural heritage should not only be seen as an instrument for (local) development in itself; the contribution of cultural heritage to other resource streams can enhance the sustainability of those resources. Therefore, cultural heritage is a resource to be taken on board in spatial planning, contributing to the sustainability of developments which have different drivers or use different types of resources. Arguments have been given to consider cultural heritage in supporting the environment-driven sustainable efforts of society today.

The elaboration of the Sustainable Management and Development framework primarily addressed social and economic dimensions. Taking local sustainable development at the core, as sustainable planning should do, the four possible fields of action (components) of the framework were identified and discussed. The discussion of those components demonstrated the interaction and synergies between the various pillars of sustainable development. This explains how the preservation of the values of cultural heritage, which define its heritage qualities, cannot be properly undertaken unless a variety of complementary components are present or pursued.

\section{References}

Bowitz, E. and K. Ibenholt (2009), 'Economic impacts of cultural heritage research and perspectives', Journal of Cultural Heritage, 10, 1-8.

Canziani, A. and R. Moioli (2010), 'The learning-based cultural district and the Monza and Brianza case. Learning from cultural heritage', in M. Mälkki and K. Schmidt-Thomé (eds), Integrating Aims. Built Heritage in Social and Economic Development, Aalto, Finland: Aalto University (Centre for Urban and Regional Studies Publications), 157-79.

CHCfE Consortium (2015), Cultural Heritage Counts for Europe, funded by the EU Culture Programme (2007-13), 295. ISBN: 978-83-63463-27-4: http://blogs.encatc .org/culturalheritagecountsforeurope/outcomes/ (accessed 22 July 2020).

Della Torre, S. (2010), 'Preventiva, integrata, programmata: le logiche coevolutive della conservazione', in G. Biscontin and G. Driussi (eds), Pensare la prevenzione: manufatti, usi, ambienti, Atti del convegno, Venice: Arcadia Ricerche, 67-76. 
Dieleman, H. (2013), 'Organizational learning for resilient cities, through realizing eco-cultural innovations', Journal of Cleaner Production, 50, 171-80.

European Agenda for Culture in a Globalizing World (2007), Communication from the Commission to the European Parliament, the Council, the European Economic and Social Committee and the Committee of the Regions, adopted on 10/05/2007 (COM(2007) 242 final).

Folke, C. (2006), 'Resilience: the emergence of a perspective for social-ecological systems analyses', Global Environmental Change, 16, 253-67.

Fox, W. and E. Van Rooyen (2004), The Quest for Sustainable Development, Cape Town: Juta Academic.

Galison, P. (1997), Image \& Logic: A Material Culture of Microphysics, Chicago, IL: University of Chicago Press.

Gallacher, P. (2005), Everyday Spaces: The Potential of Neighbourhood Space, London: Thomas Telford.

Gustafsson, C. (2009), 'The Halland Model. A trading zone in concert with labour market policy and the construction industry, aiming at regional sustainable development', Göteborg: doctoral dissertation, Chalmers University of Technology.

Hangzhou Declaration (2013), http://www.unesco.org/new/fileadmin/MULTIMEDIA/ HQ/CLT/images/FinalHangzhouDeclaration20130517.pdf (accessed 22 July 2020).

Hawkes, J. (2001), The Fourth Pillar of Sustainability: Culture's Essential Role in Public Planning, Melbourne: Cultural Development Network, 70 . ISBN: 1863350497.

Hewison, R. and J. Holden (2006), 'Public value as a framework for analysing the value of heritage: the ideas', in K. Clark (ed.), Capturing the Public Value of Heritage: The Proceedings of the London Conference 25-26 January 2006, London: English Heritage.

Holden, M. (2010), 'Public participation and local sustainability: questioning a common agenda in urban governance', International Journal of Urban and Regional Research, 35(2), 312-29.

Hutchings, J. and S. Corr (2012), 'A framework for access to the conservation-restoration profession via the mapping of its specialist competencies', Higher Education, 63, 439-54.

Innes, J. (1995), 'Planning theory's emerging paradigm: communicative action and interactive practice', Journal of Planning Education and Research, 14, 183-9: 185.

Isserman, A., E. Feser and D. Warren (2009), 'Why some rural places prosper and others do not', International Regional Science Review, 32(3), 300-42.

Kohler, N., P. Steadman and U. Hassler (2009), 'Research on the building stock and its applications', Building Research and Information, 37(5-6), 449-54.

Lampis, A. (2009), 'Marketing, capability building and increasing of cultural needs: the Bolzano Province experience', in F. Putigano (ed.), Learning Districts: patrimonio culturale, conoscenza e sviluppo locale, Milan, Maggioli Editore: Sant'Arcangelo di Romagna, 61-73.

Lidelow, S., T. Örn, A. Luciani and A. Rizzo (2019), 'Energy-efficiency measures for heritage buildings: a literature review', Sustainable Cities and Society, 45, 231-42.

Loorbach, D. (2007), 'Transition management: new mode of governance for sustainable development', PhD dissertation, Rotterdam: Erasmus Universiteit Rotterdam.

Magalhães, C., P. Healey and A. Madanipour (2002), 'Assessing institutional capacity for city centre regeneration: Newcastle's Grainger Town', in G. Cars, P. Healey, A. Madanipour and C. Magalhães (eds), Urban Governance, Institutional Capacity and Social Milieux, Hampshire: Ashgate Publishing, 45-64. 
Pickard, R. (2009), Funding the Architectural Heritage: A Guide to Policies and Examples, Strasbourg: Council of Europe.

Pickard, R. (2011), 'Funding sources and strategies', Context, 118, 12-15.

Putnam, R. (1993), Making Democracy Work: Civic Traditions in Modern Italy, Princeton, NJ: Princeton University Press.

Smedby, N. and L. Neij (2013), 'Experiences in urban governance for sustainability: the constructive dialogue in Swedish municipalities', Journal of Cleaner Production, 50, 148-58.

Smith, L., A. Morgan and A. Van Der Meer (2003), 'Community-driven research in cultural heritage management: the Waanyi Women's History Project', International Journal of Heritage Studies, 9(1), 65-80.

Sustainable Development Goals (2015), Transforming Our World: The 2030 Agenda for Sustainable Development. https://sustainabledevelopment.un.org/post2015/ transformingourworld (accessed 29 May 2020).

Swallow, P. (1997), 'Managing unoccupied buildings and sites', Structural Survey, 15(2), 74-9.

Swensen, G., G. Jerpasen, O. Saeter and M. Tveit (2012), 'Alternative perspectives? The implementation of public participation in local heritage planning', Norsk Geografisk Tidsskrift - Norwegian Journal of Geography, 66(4), 213-26.

Throsby, D. (1997), 'Sustainability and culture: some theoretical issues', International Journal of Cultural Policy, 4(1), 7-19.

Tidball, K. and M. Krasny (2007), 'From risk to resilience: what role for community greening and civic ecology in cities?', in A. Wals (ed.), Social Learning Towards a More Sustainable World, Wageningen: Academic Press, 149-64.

Van Balen, K. (2015), 'Preventive conservation of historic buildings', International Journal for Restoration of Buildings and Monuments, 21(2), 99-104.

Van Balen, K. and A. Vandesande (2015), 'Community involvement in heritage', a series by the Raymond Lemaire International Centre for Conservation, vol. 1, Antwerp: Garant.

Vandesande, A. (2017), 'Preventive conservation strategy for built heritage aimed at sustainable management and local development', $\mathrm{PhD}$ thesis for the degree of Doctor of Engineering Science, Civil Engineering, KU Leuven.

Vandesande, A., O. Vileikis, K. Van Balen and M. Santana Quintero (2012), 'A value mapping tool for assessing archaeological ensembles', in Proceedings of the First International Conference on Best Practices in World Heritage: Archaeology (1007-22). Presented at the First International Conference on Best Practices in World Heritage: Archaeology, Menorca, 9-13 April 2012. ISBN: 978-84-695-6782-1.

WCED (World Commission on Environment and Development) (1987), Our Common Future: Report of the World Commission on Environment and Development, Oxford: Oxford University Press.

Wood, B. (2005), 'Towards innovative building maintenance', Structural Survey, 23(4), 291-7.

World Bank (2002), Social Development Update: Monitoring Civic Engagement in Bank Lending and Policy Instruments, Washington DC. 